\title{
Mechanistic Insight into the Framework Methylation of H-ZSM-5 for Varying Methanol Loadings and Si/AI Ratios Using First-Principles Molecular Dynamics Simulations
}

\author{
Stefan A. F. Nastase, Pieter Cnudde,* Louis Vanduyfhuys, Kristof De Wispelaere, \\ Veronique Van Speybroeck,* C. Richard A. Catlow, and Andrew J. Logsdail*
}

Cite This: ACS Catal. 2020, 10, 8904-8915

Read Online

ABSTRACT: The methanol-to-hydrocarbon process is known to proceed autocatalytically in H-ZSM-5 after an induction period where framework methoxy species are formed. In this work, we provide mechanistic insight into the framework methylation within H-ZSM-5 at high methanol loadings and varying acid site densities by means of first-principles molecular dynamics simulations. The molecular dynamics simulations show that stable methanol clusters form in the zeolite pores, and these clusters commonly deprotonate the active site; however, the cluster size is dependent on the temperature and acid site density. Enhanced sampling molecular dynamics simulations give evidence that the barrier for methanol conversion is significantly affected by the neighborhood of an additional acid site, suggesting that cooperative effects

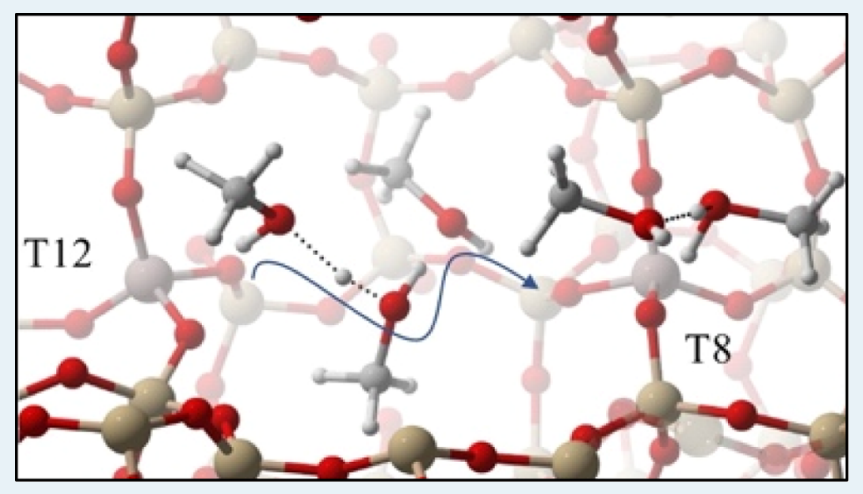
influence methanol clustering and reactivity. The insights obtained are important steps in optimizing the catalyst and engineering the induction period of the methanol-to-hydrocarbon process.

KEYWORDS: zeolite, acidity, methanol, methylation, methanol-to-hydrocarbons, metadynamics

\section{INTRODUCTION}

Reducing society's fossil fuel dependence is at the forefront of current research developments, with alternative carbon sources, such as biomass, projected to secure a sustainable production of fuels and fine chemicals. ${ }^{1-4}$ Methanol can be produced from biomass-derived syngas, which can then be converted to a wide range of useful hydrocarbons using zeolite catalysts. $^{5-7}$ The methanol-to-hydrocarbon (MTH) process is a promising technology to bypass crude oil in the production of fuel and light olefins and is now used on an industrial scale; ${ }^{3,8}$ however, controlling the product selectivity and deactivation rate remains a challenge. ${ }^{3,8,9}$

Currently, there is a broad agreement on the general aspects of the successive steps taking place during the MTH chemistry, as outlined in Scheme 1. The MTH process is characterized by a kinetic induction period, a state of low methanol reactivity during which the first $\mathrm{C}-\mathrm{C}$ bonds are formed. Then, the first hydrocarbon pool (HP) species are formed, which act as a

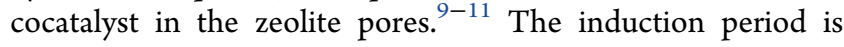
followed by a steady-state process in which, depending on the zeolite topology and reaction conditions, a broad spectrum of hydrocarbons from alkenes to aromatics, such as polymethoxybenzyl species, may be formed. ${ }^{6,8,12}$ As illustrated in Scheme 1 , the steady-state regime consists of two autocatalytic reaction cycles in which subsequent methylation and olefin elimination reactions lead to the formation of olefins.

Apart from direct methylation, it is known that adsorbed methanol forms framework-bound methoxide species when passed over the catalyst. These methoxide species then may further take an active role, similar to methanol, being involved in several reaction steps, up to the formation of small olefins and aromatic hydrocarbons. ${ }^{13-17}$ Wang et al. reported that a pure, methylated zeolite $\left(\mathrm{CH}_{3}-\mathrm{ZSM}-5, \mathrm{CH}_{3}-\mathrm{Y}\right.$, or $\mathrm{CH}_{3}-\mathrm{SAPO}$ $34)$ could be heated $(523 \mathrm{~K})$ without reagents to produce paraffins, olefins, and aromatics, ${ }^{16,17}$ illustrating that the methyl moiety by itself can participate in the MTH process. In addition, controlling the rate of the methylation process can influence the deactivation rate; conversion of aromatics to polycyclic compounds was reported when the zeolite pores became blocked, thus deactivating the catalyst. ${ }^{18,19}$

Received: March 30, 2020

Revised: July 8, 2020

Published: July 12, 2020 
Scheme 1. Outline of MTH Process with the Reaction Step of Focus for Our Study, Also Part of the Induction Period, Encapsulated with a Dashed Line

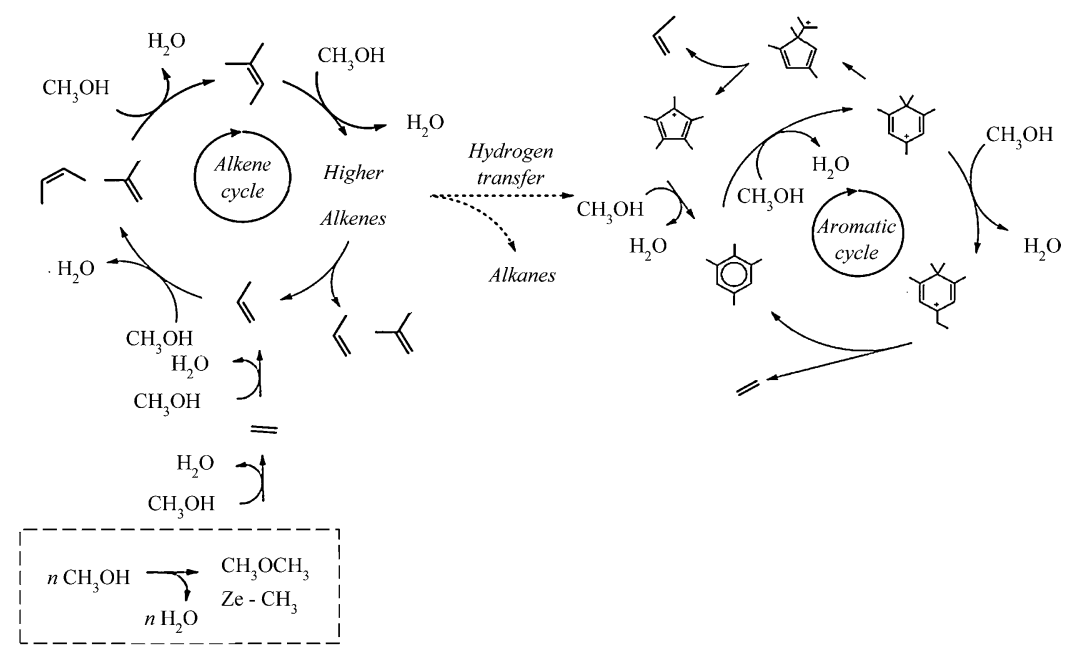

Detailed studies have been performed to investigate the competition between the concerted methylation (direct reaction of methanol) and stepwise methylation (reaction via methoxy groups $)^{20}$ of small olefins and aromatics. ${ }^{21}$ Both mechanisms may occur and the prevailing mechanism largely depends on the catalyst topology and the operating conditions. $^{20,22-24}$ This competition in mechanisms is also corroborated by Fourier transform infrared (FTIR) spectroscopy $^{18-20,25-27}$ and magic-angle nuclear magnetic resonance (NMR) spectroscopy. ${ }^{16,21,22,28}$ Early experimental investigations suggested that the framework methylation can occur spontaneously at room temperature, ${ }^{29}$ thus making it unclear how conditions affect the methylation process. The lowtemperature framework methylation was recently validated by diffuse reflectance infrared Fourier transform spectroscopy (DRIFTS), quasielastic neutron scattering (QENS), and inelastic neutron scattering (INS) experiments. ${ }^{30-32}$ These studies highlighted that, when employing specific conditions, namely, a high methanol loading (at least three methanol molecules per acid site) and a Si/Al ratio of 30, the framework methylation takes place in H-ZSM-5 but not in H-Y. ${ }^{31}$ Both experimental and theoretical ${ }^{33}$ investigations showed that this reaction may occur faster when increasing the methanol loading because of the formation of methanol clusters that facilitate a spontaneous proton transfer. The detachment of the proton from the zeolite framework is thought to lower the methylation activation barrier; however, it is still unclear how the room-temperature methylation occurs.

First-principles simulation techniques are a valuable tool to obtain mechanistic insight into elementary reaction steps. Such approaches lead to a better understanding of experimental observations. Early studies of the MTH process modelled methylation reactions with static methods on small cluster models of the zeolite framework, which neglected the role of the extended zeolite lattice on the stability of the transition state. $^{24,34}$ Later reports suggested that confinement effects of the zeolite lowered the methylation barrier by $40 \mathrm{~kJ} / \mathrm{mol}^{35}$ Although static calculations may help to identify the transition states for elementary reactions, modeling the complex MTH environment consisting of several methanol $(\mathrm{MeOH})$, dimethyl ether (DME), and HP species at operating conditions is not straightforward. In contrast, molecular dynamics (MD) techniques, which sample a larger part of the energy surface, can account for the configurational freedom of high methanol loadings and a high acid site density. Recently, enhanced sampling MD methods have been successfully used within the context of zeolite-catalyzed reactions. ${ }^{21,36,37}$ For example, the metadynamics (MTD) technique has been applied to analyze the role of methanol loading on the methylation of H-ZSM-5 at high temperatures $(623 \mathrm{~K})$. The resulting energy barrier was observed to be considerably lower $(139 \pm 2 \mathrm{~kJ} / \mathrm{mol})$ than in previous static calculations $(154 \mathrm{~kJ} / \mathrm{mol}) .^{21}$

This study aims to give mechanistic insight with respect to the spontaneous conversion of methanol within H-ZSM-5, at room temperature, by analyzing the effect of higher methanol loadings and acid site density on the methylation reaction. We perform $a b$ initio MD simulations at conditions that mimic the experiments where low-temperature methylation was observed within H-ZSM-5. MTD simulations are also applied to investigate how the clustering of methanol molecules around the active site leads to activation and formation of a methoxylated framework. We consider specifically the dynamics of the methanol molecules and their interaction with the Brønsted acid sites on the zeolite catalyst.

\section{METHODOLOGY}

2.1. Catalyst Model. The H-ZSM-5 catalyst is represented by a unit cell model, which is periodically extended in three dimensions. The orthorhombic unit cell of the ZSM-5 zeolite (MFI topology) contains 96 tetrahedrally coordinated (T) atoms. The unit cell parameters, presented in Table S1 of the Supporting Information, were averaged from a preliminary 50 ps MD simulation in the isothermal-isobaric (NPT) ensemble on the empty zeolite cells, with one and two acid sites per unit cell as appropriate. Brønsted acid sites are created by substituting a $\mathrm{Si} \mathrm{T}$-site in the parent crystal by a trivalent $\mathrm{Al}$ atom and adding a charge-compensating proton on an adjacent oxygen. In order to quantify the interactions between the active site and the methanol reactants, we modelled the H-ZSM-5 catalyst with one or two acid sites per unit cell, corresponding to a $\mathrm{Si} / \mathrm{Al}$ ratio of 95 and 47, respectively. This model does not match exactly the referenced experimental conditions $(\mathrm{Si} / \mathrm{Al}=$ 30 , corresponding to approx. three acid sites per unit cell $)^{31}$ but allows us to characterize the effects of acid site isolation 
and potential concerted interaction. For the single acid site model, the $\mathrm{Al}$ substituent is situated in the $\mathrm{T} 12$ position at the intersection of the straight and zigzag channels in the MFI structure. For the model with two acid sites, the second Al substitution occurs in the T8 position, also at the intersection of straight and zigzag channels, being three T-sites apart. ${ }^{35,38}$ The choice of those particular sites satisfies both Loewenstein's $^{39}$ and Dempsey's ${ }^{40}$ rules and allows testing of the viability for the "pairing" of sites, as proposed in previous experimental studies. ${ }^{41}$

Various methanol loadings are studied in our catalyst model. One, three, or five methanol molecules are evenly distributed in the intersection pore that contains the acid sites. These loadings are well below the maximum number of methanol molecules that could be adsorbed per unit cell, as determined from a thermodynamic model based on the pore volume, guest, and interaction strength; ${ }^{42,43}$ more details are given in section S2 of the Supporting Information. The maximum loading considered (five methanol molecules per unit cell) is slightly less than experimental conditions (three methanol molecules per acid site $)^{30,31}$ but proves sufficient in our simulations in order to observe the effect of clustering on reactivity.

2.2. Molecular dynamics. 2.2.1. Ab Initio MD Simulations. $A b$ initio $\mathrm{MD}$ simulations were performed with the CP2K simulation package (version 6.1). ${ }^{44}$ The dynamics of the nuclei was governed by the Newtonian equations of motion, in which the potential from the Born-Oppenheimer electronic ground state is inserted. The self-consistent field (SCF) energy was evaluated with density functional theory using the revPBE functional ${ }^{45}$ with Grimme D3 dispersion corrections ${ }^{46}$ and the Gaussian plane wave method ${ }^{47}$ that uses a combination of Gaussian basis functions (DZVP-GTH ${ }^{48}$ ) and plane waves (320 Ry cutoff). The SCF convergence criterion was set to $1 \times$ $10^{-5}$ Hartree between SCF iterations. The integration time step was set to 0.5 fs. For the various complexes, a 50 ps MD production run is carried out in the NVT ensemble at $300 \mathrm{~K}$, controlled by a chain of five Nosé-Hoover thermostats. ${ }^{49-51}$ The cell volume was fixed to the cell parameters from the preliminary NPT simulation on the empty cell, where the pressure of $1 \mathrm{~atm}$ was controlled by a Martina-Tobias-Klein barostat. $^{51}$ Trajectory snapshots are taken every 1 fs of the 50 ps NVT production run.

2.2.2. Structural Analysis. 2.2.2.1. Geometric Analysis. To understand and quantify the geometric features of our simulations, we tracked a range of bond lengths and determined the average distance and standard deviation along the MD trajectories (Figure 1).

Additionally, a more in-depth approach was taken to determine the stability of the methanol cluster around the active site. As illustrated in Figure 2, the distance is calculated between the geometrical center for the oxygen atoms in the clustered methanol molecules (M) and the geometric center for the three oxygen atoms exposed to the methanol cluster at the active site (A). To quantify the overall interaction of multiple acid sites with the methanol cluster when a second acid site is considered, the variation of the distance of the methanol cluster between the two acid sites is analyzed, which is done by determining the distance between the center of the methanol cluster and the geometric center of the smallest zeolite ring containing the two aluminum atoms and neighboring silicon atoms, (R) (Figure 2).

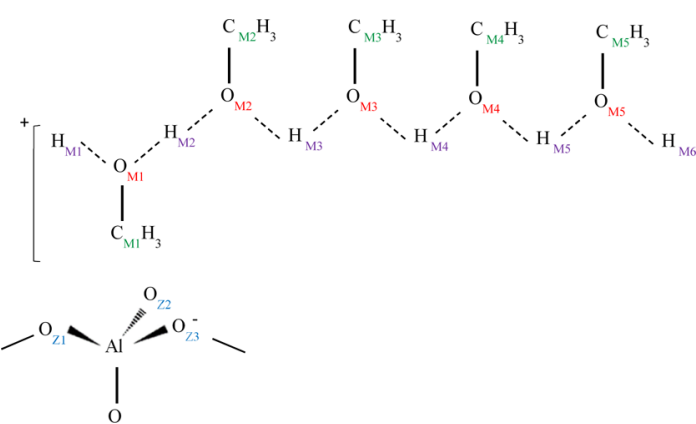

Figure 1. Schematic representation of parameters used for structural analysis in the MD simulations. The analyzed intra- and intermolecular distances are between hydrogen and nearest methanol oxygen, $d\left(\mathrm{O}_{\mathrm{M} 1-5}-\mathrm{H}_{\mathrm{M} 1-6}\right)$, methanol oxygen atoms, $d\left(\mathrm{O}_{\mathrm{M} 1-\mathrm{M} 5}-\right.$ $\left.\mathrm{O}_{\mathrm{M} 1-\mathrm{MS}}\right)$, and carbon atoms, $d\left(\mathrm{C}_{\mathrm{M} 1-5}-\mathrm{C}_{\mathrm{M} 1-5}\right)$, where indices denote the parent methanol cluster of the atom of interest.

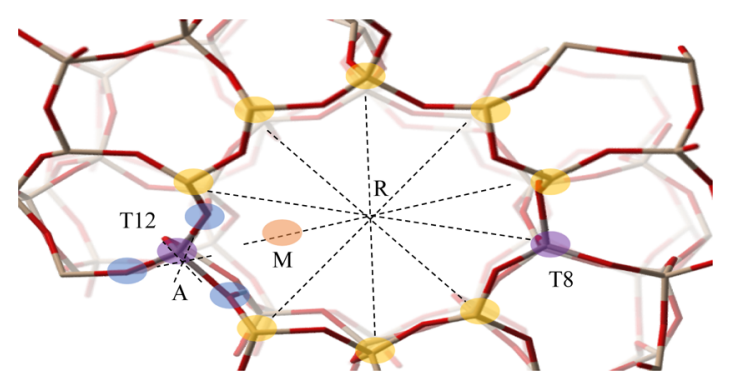

Figure 2. Distances measured between both the center of the active site $(A)$ and the center of the aluminum ring $(R)$ and the center of the methanol cluster (M) with $\mathrm{Al}$ - purple, Si-yellow, O-red, and $\mathrm{H}-$ white, with methanol molecules eliminated from the figure for a clear view of the geometric points used as the reference.

2.2.2.2. Protonation Effects. We determined the distance between the Brønsted proton, coadsorbates, and zeolite sites by measuring the length of the $\mathrm{O}-\mathrm{H}$ bonds in the methanol cluster, allowing us to conduct a statistical analysis of the protonation effects. Specifically, the probability of the zeolite site being deprotonated and methanol being protonated by the Brønsted proton is calculated as a percentage of time, wherein the $\mathrm{O}-\mathrm{H}$ bond length between the Brønsted proton and a methanol oxygen is less than or equal to $1.2 \AA$. We also analyzed the position of the Brønsted proton in the methanol cluster by determining the percentage of time where a methanol molecule would simultaneously have two $\mathrm{O}-\mathrm{H}$ bonds less or equal to $1.2 \AA$.

2.2.2.3. Clustering Probability. The distance between the neighboring methanol molecules, $d\left(\mathrm{O}_{\mathrm{M}}-\mathrm{O}_{\mathrm{M}}\right)$, was used to quantify the probability of methanol clustering by considering a distance threshold equal to or less than 3.0 $\AA$. This distance represents the sum of the $\mathrm{O}-\mathrm{H}$ covalent bond of a methyloxonium molecule (1.5 ̊) and a strong hydrogen bond $(1.5 \AA)$ as determined from previous theoretical calculations $^{52}$ and is similar to previous experimental findings. ${ }^{53}$ We note that the methanol molecules do not change position significantly in the methanol clusters, based on the minimum and maximum distances tabulated in Tables S2 and S3 and Section S3 of the Supporting Information, particularly the $d\left(\mathrm{O}_{\mathrm{M}}-\mathrm{O}_{\mathrm{M}}\right)$ lengths. Furthermore, this analysis takes into account the simultaneous presence of different types of clusters. 
2.3. Metadynamics. To accelerate the sampling of the activated transition from methanol to methoxide, the MTD approach was employed. ${ }^{44,54-56}$ Gaussian hills with an initial height of $5 \mathrm{~kJ} / \mathrm{mol}$ and width of 0.02 are added every $25 \mathrm{fs}$ along two collective variables (CVs). These settings were previously shown to give accurate results for similar methylation reactions in $\mathrm{H}-\mathrm{ZSM}-5 \mathrm{~S}^{21}$ The $\mathrm{CV}$ s are defined by coordination numbers $(\mathrm{CNs})$ selected to uniquely describe each state of the reaction

$$
\mathrm{CN}(i, j)=\sum_{\substack{i \in I \\ j \in J}} \frac{1-\left(r_{i j} / r_{0}\right)^{n}}{1-\left(r_{i j} / r_{0}\right)^{m}}
$$

in which $r_{i j}$ is the distance between atoms $i$ and $j$. The parameters $n$ and $m$ were set to 6 and 12, respectively. The reference distance, $r_{0}$, was chosen to be similar to the transition-state distance $(2.0 \AA)$. The first CV, CV1, is defined by $\mathrm{CN}\left(\mathrm{C}_{\mathrm{MeOH}}-\mathrm{O}_{\mathrm{MeOH}}\right)$, which describes the breaking of the $\mathrm{C}-\mathrm{O}$ bond of the methanol; $\mathrm{CV} 2$ is then defined by $\mathrm{CN}\left(\mathrm{C}_{\mathrm{MeOH}}-\mathrm{O}_{\text {zeolite }}\right)$ to describe the formation of the $\mathrm{C}-\mathrm{O}$ bond between the resulting methyl moiety and the zeolite framework. Also, an additional constraint on a third CV, CV3, defined as the $\mathrm{CN}$ of the two Brønsted protons on the oxygen of the methanol reactant, is applied to keep the methanol molecule in the protonated state. Additional details on the CVs used, wall positions, and MTD settings are provided in section S4 of the Supporting Information. The MTD simulations were considered to be converged if the barriers between every 500 hills added do not differ by more than $5 \mathrm{~kJ} / \mathrm{mol}$. In order to determine the error bars, the simulation was continued such that a further 500 hills were added to the system once it had reached convergence. The error bar with respect to the transition state was then calculated as the average between the energy barrier at the moment of convergence and the energy barrier once these 500 additional energy hills had been included. The obtained 2D free energy surface is then projected on to the difference between the two CVs. The phenomenological free-energy barrier is computed by the procedure proposed by Bucko et al. ${ }^{57}$ Further details on the methodology and case studies are provided in the work of Bailleul et al. $^{58}$

\section{RESULTS AND DISCUSSION}

3.1. Methanol dynamics at Room Temperature. For each of the model systems shown in Figure 3, we performed a 50 ps $\mathrm{MD}$ simulation to analyze the dynamic adsorption behavior of the various methanol loadings. The methanol hydrogen bonding network and clustering behavior are described in Section 3.1.1, whereas the ability of the methanol cluster to deprotonate the acid site is considered in Section 3.1.2. Finally, the relative position of methanol in the zeolite channels is discussed in Section 3.1.3.

3.1.1. Methanol Configuration. Multiple methanol molecules can form stable clusters, connected by hydrogen bonds, which are able to deprotonate the acid site. At $300 \mathrm{~K}$, when having one acid site per unit cell, all methanol molecules remain connected through a hydrogen bond network and the methanol cluster is stable for the entire simulation, both for a loading of three and five methanol molecules. However, in the case of two acid sites per unit cell, the five methanol molecules are distributed as a trimer on the T12 site and a dimer at the T8 site, both of which are also stable for the entirety of the

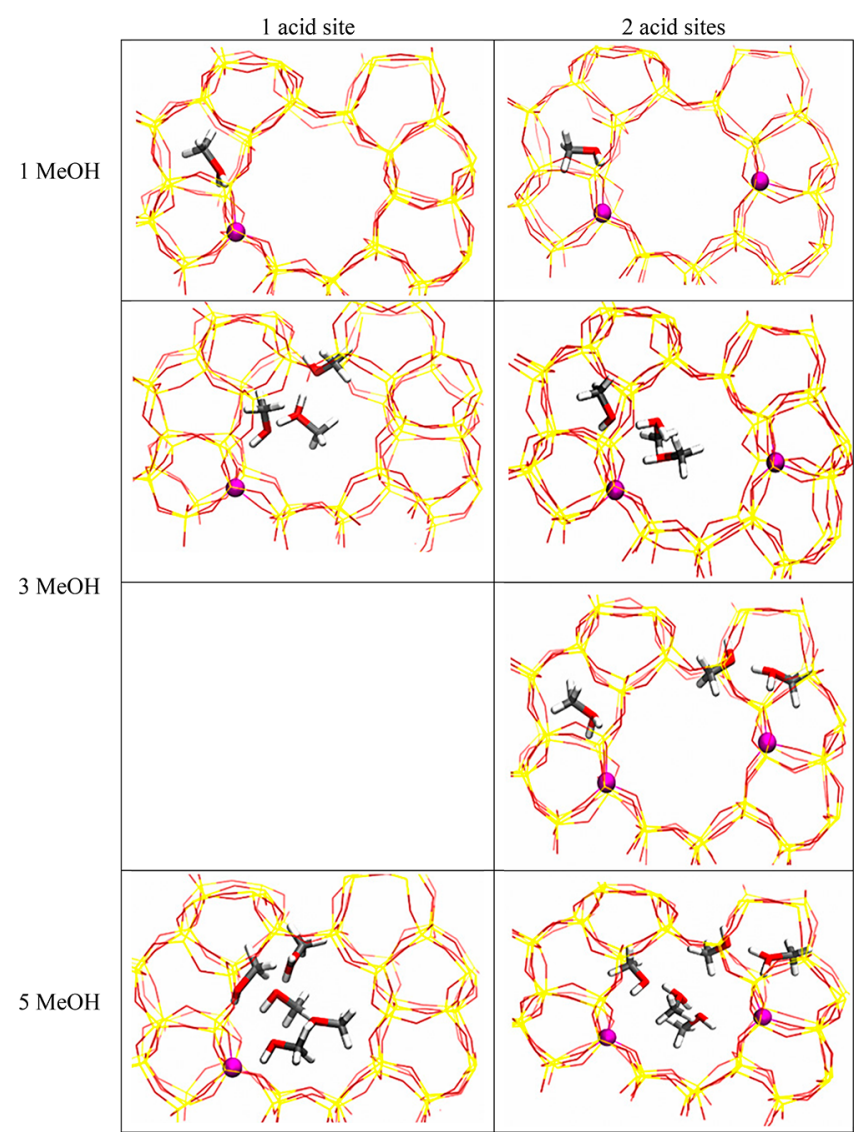

Figure 3. Equilibrated models from NPT simulations, with $\mathrm{Al}-$ purple, $\mathrm{Si}$-yellow, $\mathrm{O}-$ red, $\mathrm{C}-$ gray, and $\mathrm{H}$-white, with one acid (left column) and two acid sites (right column) per unit cell and one (top row), three (middle two rows), and five (bottom row) methanol molecules per unit cell.

production run. Methanol clustering of this nature has been observed previously in $\mathrm{MD}$ simulations (at $670 \mathrm{~K}$ ) ) $^{36}$ and correlated with experimental results; the methanol clusters match with previous infrared (IR) and calorimetric studies, where up to 11 methanol molecules are reported to adsorb around an active site when the $\mathrm{Si} / \mathrm{Al}$ ratio is $136^{59}$ and less than 3 methanol molecules are adsorbed at the active site when the $\mathrm{Si} / \mathrm{Al}$ ratio is 36 or lower, that is, the zeolite framework has a higher acid site density. ${ }^{59,60}$

To evaluate the effect of temperature on the methanol dynamics and the strength of the hydrogen bonds, we performed MD simulations on the single acid site model with five methanol molecules per unit cell both at room temperature $(300 \mathrm{~K})$ and at a typical MTH operating temperature $(670 \mathrm{~K})$. At room temperature, we find that formation of pentamers has the largest probability, whereas as in the earlier simulations, at high temperatures, trimers were found to be the most stable (Figure 4). Importantly, in both cases, the methanol clusters (trimer and pentamer) are protonated for most of the time. The sensitivity of the results was analyzed with respect to the interaction cutoff threshold, but the distribution of cluster sizes would vary by less than $5 \%$ for values of $d\left(\mathrm{O}_{\mathrm{M}}-\mathrm{O}_{\mathrm{M}}\right)$ up to $4.0 \AA$. We also note that no other types of clusters are formed from the unbonded, free moving methanol molecules other than those mentioned in Figure 4. 


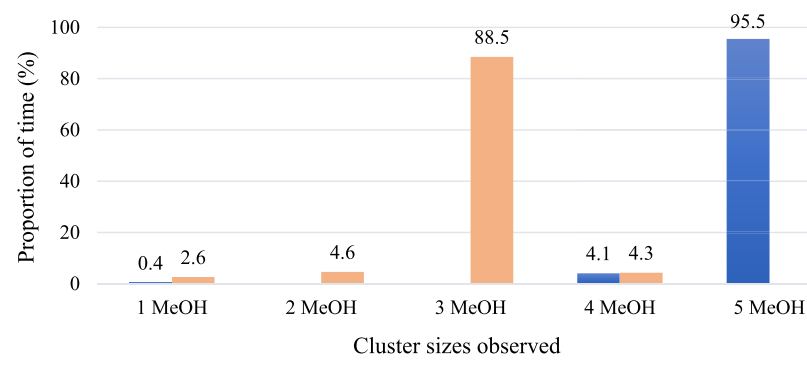

Figure 4. Proportion of simulation time for which five methanol molecules $(\mathrm{MeOH})$ were collected in clusters of size one to five molecules. Results are presented for one acid site per unit cell, with the temperature in this work at $300 \mathrm{~K}$ (blue) and at $670 \mathrm{~K}$ (orange).

At $300 \mathrm{~K}$, we see in Table 1 that the hydrogen bonds of the fourth $(1.51 \AA)$ and fifth methanol $(1.90 \AA)$ elongate, the further they are from the Brønsted proton, and these bonds eventually break once higher temperatures $(670 \mathrm{~K})$ are employed. It is expected that the size of the hydrogen-bonded protonated clusters is determined by a balance between enthalpic and entropic stabilization. Analyzing Table 1 in detail, we can see that the average distance between the methanol oxygen and the framework proton for one methanol per acid site is larger than $1.3 \AA$ in all simulations, confirming that the framework does not deprotonate; however, for three and five methanol molecules, the same distance, $d\left(\mathrm{H}_{\mathrm{M1}}-\mathrm{O}_{\mathrm{M1}}\right)$, is reduced below $1.1 \AA$ as the framework proton shifts onto methanol, forming a methoxonium $\left(\mathrm{CH}_{3} \mathrm{OH}_{2}^{+}\right)$ion within the methanol cluster. Considering the three methanol systems shown in Figure 3, we can see that an interplay between an Eigen and a Zundel configuration $\left(\mathrm{CH}_{3} \mathrm{OH}-\mathrm{H}_{\mathrm{M} 2}{ }^{+}-\mathrm{CH}_{3} \mathrm{OH}\right)$ occurs, ${ }^{61}$ with the hydrogen nuclei $\mathrm{H}_{\mathrm{M} 2}$ delocalized between the oxygen in either the first or second methanol, $\mathrm{O}_{\mathrm{M} 1}$ or $\mathrm{O}_{\mathrm{M} 2}$, respectively, on average stabilized equidistant between the two. A similar observation is made for the simulations containing five methanol molecules, though the position of the Zundel configuration in the methanol chain varies depending on the number of acid sites in the framework.

3.1.2. Methanol State. During our simulations, models with one methanol molecule adsorbed at the acid site are observed to deprotonate the zeolite framework for $\sim 10 \%$ of the overall simulation time, as calculated by comparing the distance of the Brønsted proton with the framework oxygens and the adsorbed methanol. Additional information on the single methanol deprotonation of the zeolite acid site is provided in section S5 of the Supporting Information. In contrast, increasing the methanol loading to three or five molecules per acid site results in deprotonation occurring for $\sim 90 \%$ of the simulation time, that is, framework deprotonation is greatly increased. During every simulation, regardless of methanol loading, the zeolite active site is deprotonated and reprotonated several times. Compared to a single methanol molecule, a cluster better stabilizes the positive charge. At higher methanol loadings, the proton appears to be stabilized (solvated) in the center of the methanol chain, away from the active site, as concluded by assessing the distance between neighboring oxygen and hydrogen atoms in the simulation trajectory (see Tables 1 and 2). Previous IR and NMR studies reported a clear signal

Table 2. Percentage of Time (\%) That Each Methanol $(\mathrm{MeOH})$ Molecule in the Cluster Spends as a Methoxonium Ion during the Simulation, with the Order ( $n$ th) of the Protonated Methanol Molecule Being Provided in the Second Row

\begin{tabular}{ccrcccr} 
& \multicolumn{5}{c}{ percentage of time per protonated methanol } \\
& & \multicolumn{5}{c}{$(\%)$} \\
\cline { 3 - 7 } MeOH per cell & Si/Al & 1st & 2nd & 3rd & 4th & 5th \\
3 & 95 & 25.0 & 49.8 & 25.2 & & \\
& 47 & 13.9 & 64.3 & 21.8 & & \\
5 & 95 & 4.9 & 36.9 & 52.9 & 5.3 & \\
& 47 & 27.0 & 45.1 & 27.9 & & \\
& & & & & &
\end{tabular}

for protonated methanol molecules at high reactant loadings, but in the case of low methanol loadings, the corresponding signal was mostly for the physisorbed (nonprotonated) state. $^{62-64}$ The low probability of deprotonating the zeolite framework with just one methanol molecule may explain the experimental difficulties when evaluating the conditions for activating methanol; specifically, one methanol per acid site coverage at $\sim 400 \mathrm{~K}(\mathrm{Si} / \mathrm{Al}=30) .^{62-64}$

In addition, we calculated the proportion of time for which each methanol molecule in the chain is protonated into a methoxonium ion, based on the distances between oxygen and hydrogen atoms (presented in Table 2) for the part of the simulation trajectory where the cluster remains in the protonated state.

The migration of cations from the framework, as we have observed here for the acid proton in the methanol chain, is a general effect. For example, for methanol in a $\mathrm{NaY}$ system, theoretical investigations showed that methanol facilitates migration of the $\mathrm{Na}^{+}$cation from the vicinity of the active site to the center of the pore, which influences the stability of the methanol cluster. ${ }^{65}$ The stability of the solvated cation in the center of the pore, surrounded by methanol molecules, may be due to a favorable electrostatic environment as well as the distance of the methanol cluster from the active site hindering the retransfer of the Brønsted proton from the methanol. Theoretical studies of gas-phase methanol reported that the

Table 1. Average Intra- and Intermolecular Distances between Oxygen and Hydrogen Atoms in the Methanol (MeOH) Molecules Over the Entire Trajectory Run Times, Presented in $\AA^{a}$

\begin{tabular}{|c|c|c|c|c|c|c|c|c|c|c|}
\hline $\begin{array}{l}\mathrm{MeOH} \\
\text { per cell }\end{array}$ & $\begin{array}{l}\mathrm{Si} / \mathrm{Al} \\
\text { ratio }\end{array}$ & $d\left(\mathrm{H}_{\mathrm{M} 1}-\mathrm{O}_{\mathrm{M} 1}\right)$ & $d\left(\mathrm{O}_{\mathrm{M} 1}-\mathrm{H}_{\mathrm{M} 2}\right)$ & $d\left(\mathrm{H}_{\mathrm{M} 2}-\mathrm{O}_{\mathrm{M} 2}\right)$ & $d\left(\mathrm{O}_{\mathrm{M} 2}-\mathrm{H}_{\mathrm{M} 3}\right)$ & $d\left(\mathrm{H}_{\mathrm{M} 3}-\mathrm{O}_{\mathrm{M} 3}\right)$ & $d\left(\mathrm{O}_{\mathrm{M} 3}-\mathrm{H}_{\mathrm{M} 4}\right)$ & $d\left(\mathrm{O}_{\mathrm{M} 4}-\mathrm{H}_{\mathrm{MS}}\right)$ & $d\left(\mathrm{O}_{\mathrm{M} 4}-\mathrm{H}_{\mathrm{MS}}\right)$ & $d\left(\mathrm{O}_{\mathrm{M} 5}-\mathrm{H}_{\mathrm{M} 6}\right)$ \\
\hline \multirow[t]{2}{*}{1} & 95 & 1.36 & & & & & & & & \\
\hline & 47 & 1.34 & & & & & & & & \\
\hline \multirow[t]{2}{*}{3} & 95 & 1.01 & 1.28 & 1.19 & 1.04 & 1.59 & & & & \\
\hline & 47 & 1.00 & 1.40 & 1.13 & 1.09 & 1.46 & & & & \\
\hline \multirow[t]{2}{*}{5} & 95 & 1.00 & 1.58 & 1.05 & 1.27 & 1.21 & 1.51 & 1.90 & 1.03 & 1.02 \\
\hline & 47 & 1.03 & 1.28 & 1.20 & 1.04 & 1.58 & & & & \\
\hline
\end{tabular}

${ }^{a}$ All results are from methanol adsorbed on the T12 site. 

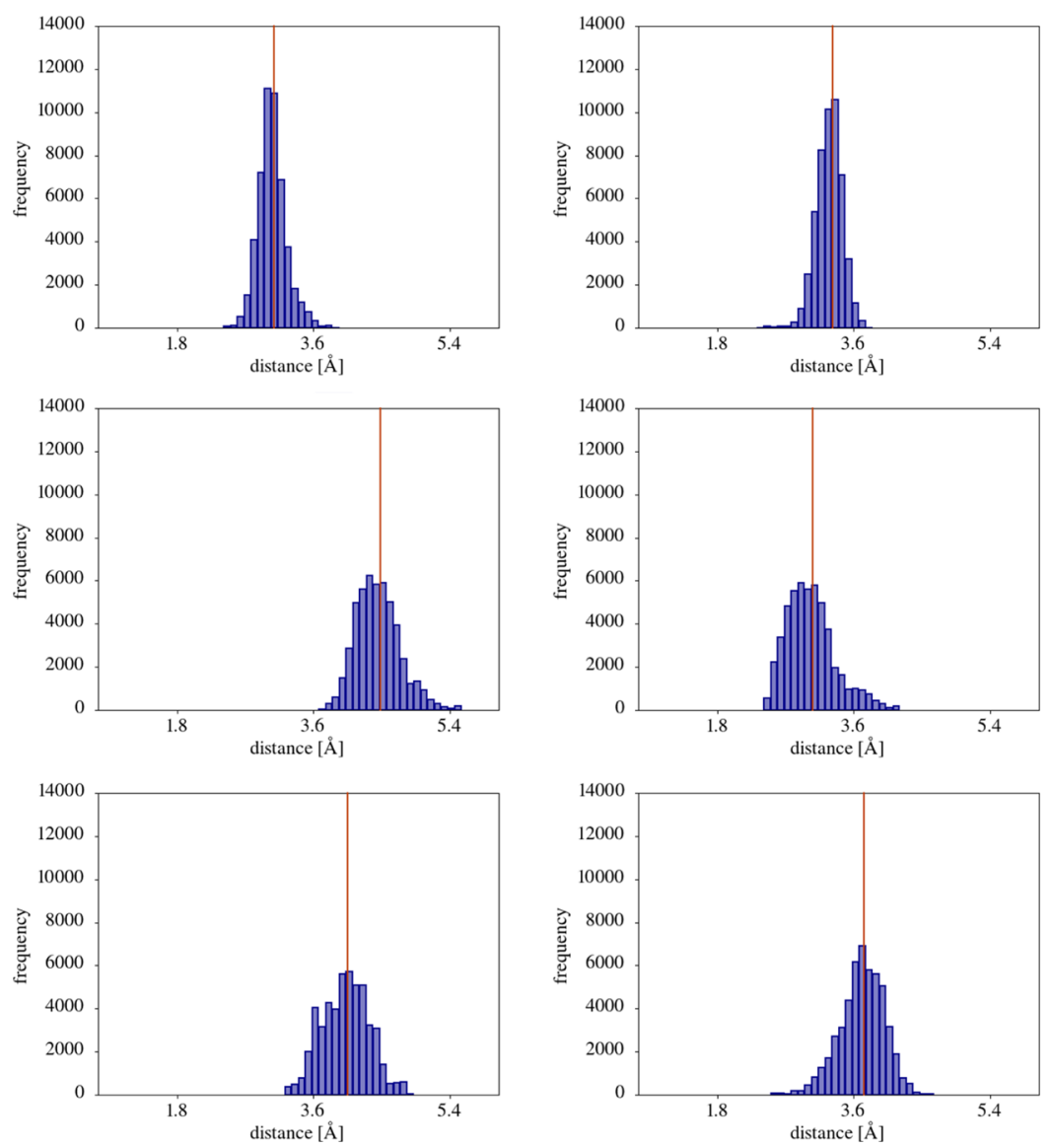

Figure 5. Histogram, during a $50 \mathrm{ps}$ simulation at $300 \mathrm{~K}$, of the distance between the center of the methanol cluster (M) adsorbed at the T12 site and the center of the exposed T12 acid site (A). Models are considered having one (left column) and two (right column) acid sites, with one (top row), three (middle row), and five (bottom row) methanol molecules per unit cell. The orange vertical line highlights the average distance.

energy to form a methanol cluster, protonated or neutral, reaches a plateau after adding five methanol molecules. The binding energy of a gas-phase five-membered protonated methanol is $\sim 150 \mathrm{~kJ} / \mathrm{mol}$, which is 5 times higher than forming a neutral cluster of the same size, which highlights the significantly enhanced stabilization of a protonated cluster ${ }^{66}$ in the zeolite environment. The same study reports the proton affinity to increase until the methanol cluster reaches three methanol molecules, with proton affinity being $1074 \mathrm{~kJ} / \mathrm{mol},{ }^{66}$ which is fairly close to the deprotonation energy of the T12 site in H-ZSM-5, $1093-1122 \mathrm{~kJ} / \mathrm{mol},{ }^{67}$ further showcasing the influence of the methanol loading on the activation of the methanol reactant. In addition, static calculations considering two methanol molecules adsorbed on the T12 zeolite acid site also reported the formation of a protonated methanol cluster and stated that the deprotonation of the zeolite by adsorbed methanol clusters is mainly influenced by energetic factors, rather than entropic effects. ${ }^{24,51}$

3.1.3. Methanol Positioning. As previously mentioned, we found that a high methanol loading can lead to the formation of methanol clusters that deprotonate the acid site. In order to rationalize the formation of methanol clusters, it is necessary to analyze further their dynamic behavior at the active site. Such information is crucial in considering both diffusivity as well as subsequent reactivity at the acid site as longer distances will alter the accessible reaction pathways. We determined the distances between the geometric center of the methanol cluster and the framework active site, as described in Section 2.2.2.
Interestingly, for one acid site per unit cell, the distance frequency analysis (Figure 5) shows that the trimer clusters stabilize further from the active site than the pentamer and monomer; we suggest that this effect could be due to the higher methanol loadings of five molecules per active site leading to compression of the methanol molecules in the pore. However, we also note that this behavior is not observed for two acid sites per unit cell; instead, the protonated trimer appears to be repelled by the second (positively charged) Brønsted site, leading to the trimer configuration being closer toward the first active site. Similar behavior is also observed for the pentamer methanol cluster, which is closer toward one particular active site when there are two acid sites in the zeolite model, though the effects are less pronounced.

The effect of the second acid site on the methanol cluster was further analyzed by determining the distance between the methanol cluster and the center of the zeolite ring that contained the two acid sites, positioned at T12 and T8 in the zeolite, as described in Section 2.2.2. When there is only one acid site in the unit cell, the distance between methanol molecules and the center of the zeolite ring decreases with increasing quantity of methanol molecules (Figure 6). This behavior is expected as it becomes more difficult for the methanol molecules to cluster around the single acid site with increased loading, and so the geometric center shifts toward the center of the pore. The position of the methanol cluster is less clearly defined when there are two acid sites in the unit cell. For a methanol monomer, the distance between the acid 

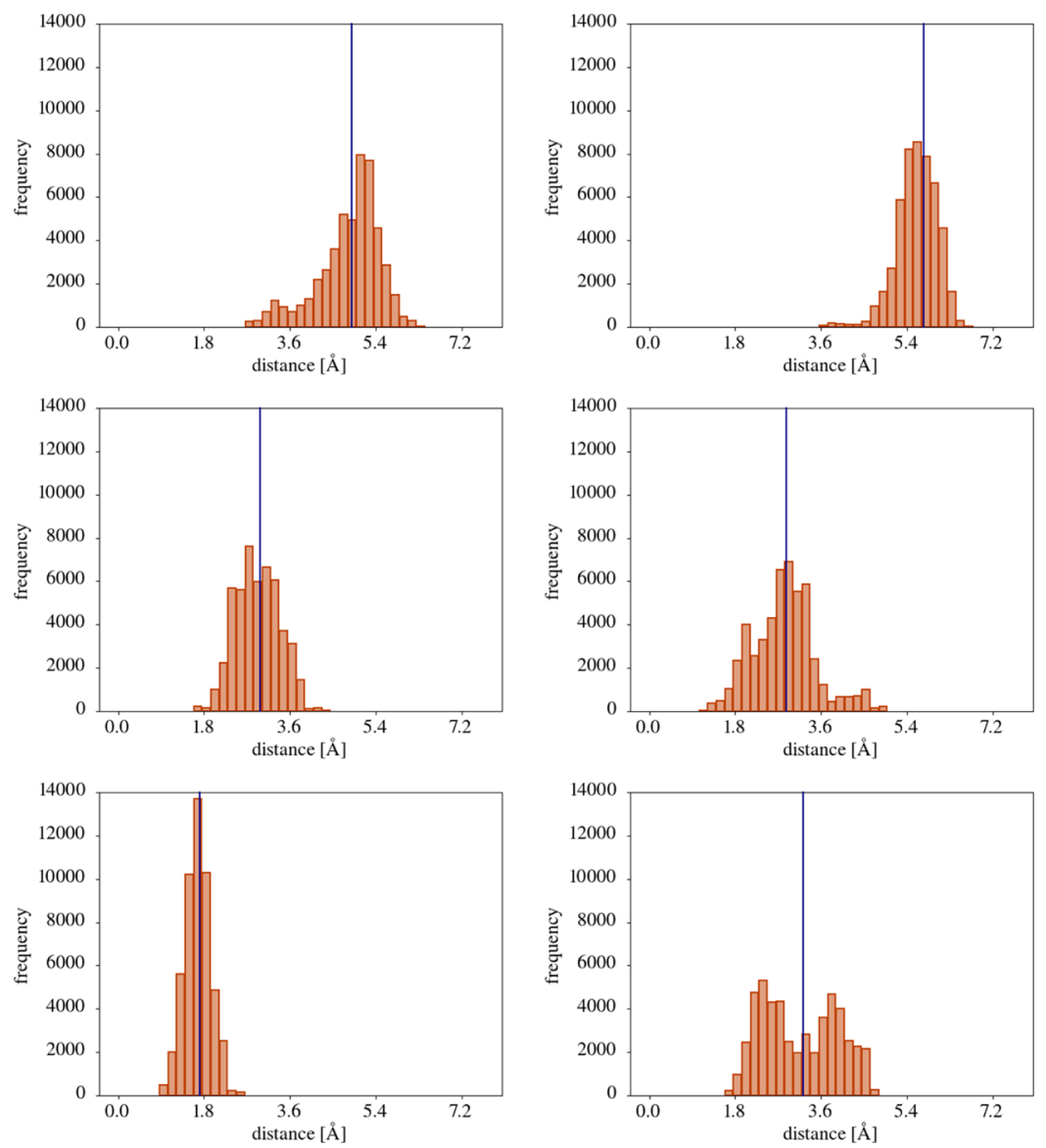

Figure 6. Histogram, during $50 \mathrm{ps}$ simulation at $300 \mathrm{~K}$, of the distance between the geometric center of the methanol cluster (M) adsorbed at the T12 site and the center of the zeolite pore (R). Models are considered having one (left column) and two (right column) acid sites, with one (top row), three (middle row), and five (bottom row) methanol molecules per unit cell. The dark-blue vertical line highlights the average distance.

site and the methanol monomer slightly increases (Figure 5), and the distance between the methanol monomer and the center of the pore also increases (Figure 6). For a methanol trimer, the mean distance between the center of the methanol cluster and the center of the zeolite ring remains constant, though with a great variance especially toward high distances. Finally, for pentamers in a system with two acid sites, a bimodal distribution is observed with distances of $\sim 2.4$ and $\sim 3.8 \AA$ prominent, which are significantly greater than the average of $1.8 \AA$ observed for the simulations with five methanol molecules in a system with a single acid site. In addition to the above, the time-dependent variation of the distance between the methanol cluster and the center of the zeolite ring, provided in section S6 of Supporting Information, also highlights a sudden change in the position of the methanol cluster with respect to the center of the ring when an additional acid site is present, which contributes to the bimodal appearance observed in Figure 6 for five methanol molecules.

3.2. Framework Methylation. Spontaneous conversion of methanol to framework methoxide groups was not observed in regular MD simulations, which is expected as methylation is an activated process. To sample methylation events, we employed enhanced sampling MD simulations, as explained in Section 2.3. In Figures 5 and 6 of Section 3.1.3, the histograms for the methanol monomer show similar profiles when the molecule is adsorbed in a unit cell with one or two acid sites. The distance between the methanol molecule and the center of the active site is larger by $0.24 \AA$ in the case of two acid sites per unit cell.
These observations indicate that the dynamic behavior of a single methanol molecule adsorbed in a unit cell having one or two acid sites is similar. Therefore, the analysis of the single methanol methylation was limited to just the single acid site per unit cell case. The calculated methylation phenomenological free-energy barriers $\left(\Delta F^{\ddagger}\right)$ are given in Table 3 alongside the reversible work between the free-energy minimum and transition state $(\Delta F)$ obtained using, as a reference for the reactant state, the lowest energy state sampled in the local minimum population, as opposed to the highest energy state employed to determine the phenomenological

Table 3. Reversible Work between the Free-Energy Minimum and Transition State $(\Delta F)$ and Phenomenological Free-Energy Barriers $\left(\Delta F^{\ddagger}\right)$ for Zeolite Methylation, Presented in $\mathrm{kJ} / \mathrm{mol}$, with $\Delta F$ Having the Same Error Bars as the Phenomenological Barriers

\begin{tabular}{|c|c|c|c|c|}
\hline \multirow[b]{2}{*}{$\mathrm{Si} / \mathrm{Al}$ ratio } & \multirow[b]{2}{*}{ methanol/u.c. } & \multicolumn{2}{|c|}{ this study $(300 \mathrm{~K})$} & ref $21(623 \mathrm{~K})$ \\
\hline & & $\Delta F^{\ddagger}$ & $\Delta F$ & $\Delta F$ \\
\hline 95 & $1 \mathrm{MeOH}$ & $142 \pm 3$ & 160 & $160 \pm 5$ \\
\hline 95 & $3 \mathrm{MeOH}$ & $169 \pm 5$ & 171 & \\
\hline 47 & & $142 \pm 2$ & 152 & \\
\hline 95 & $5 \mathrm{MeOH}$ & $149 \pm 2$ & 156 & $139 \pm 2^{a}$ \\
\hline 47 & & $112 \pm 2$ & 119 & \\
\hline
\end{tabular}

${ }^{a}$ Results from the conversion of methanol coadsorbed with three methanol molecules and one water molecule. 


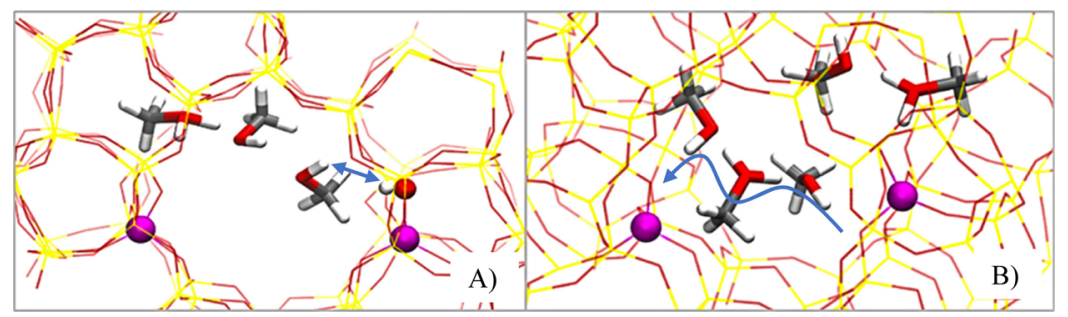

Figure 7. MTD simulation snapshot of (A) three $\mathrm{MeOH}$ and (B) five $\mathrm{MeOH}$ molecules per unit cell $(\mathrm{Si} / \mathrm{Al}=47)$ with blue arrow highlighting the (A) repulsion effect between the Bronsted proton and that of the methanol and (B) the polarization effect of the T8 site along the hydroxyl groups. The key is as per Figure 3.

barrier, as explained in Section 2.3. For comparison, the values obtained in the work of Van Der Mynsbrugge et al. ${ }^{21}$ are also displayed in Table 3.

Previously, based on static calculations, activation barriers of $225 \mathrm{~kJ} / \mathrm{mol}$ (for single methanol methylation) and $184 \mathrm{~kJ} / \mathrm{mol}$ (two methanol methylation) were reported. ${ }^{33}$ Similarly, we also find that the activation barrier varies with methanol loading, although not as significantly as proposed in earlier studies. $^{24,33,34}$ These earlier studies mainly employed small clusters, ${ }^{24,34}$ where the overall stabilization of the lattice may not have been sufficiently taken into account, giving larger changes when adding more methanol molecules; in work using periodic models, lower levels of theory may not have correctly represented the chemical environment. ${ }^{33}$ Irrespective of the simulation approach, some caution should be taken in directly comparing statically and dynamically obtained barriers, as the sampling of the reactant state might be slightly different. ${ }^{58}$ Specifically, static calculations of methanol in H-ZSM-5 commonly consider the single methanol molecule adsorbed in a nonprotonated state as the reference. In contrast, in our MD and MTD simulations, a single methanol is also sampled in the protonated state, which eliminates the protonation step necessary in static calculations and leads to a limited difference between an unassisted (i.e., single) and assisted methylation (i.e., multiple methanol molecules). To quantify the difference between using a protonated or nonprotonated methanol as the reference reactant state, when determining the methylation barrier, the free energy and phenomenological free-energy barriers were compared. The reversible work between the freeenergy minimum and transition state $(\Delta F)$ uses the sampled metastable intermediate, that is, protonated methanol, and is $\sim 20 \mathrm{~kJ} / \mathrm{mol}$ greater than the phenomenological free-energy barrier $\left(\Delta F^{\ddagger}\right)$, which is based on the stable nonprotonated configuration.

When comparing the activation free energies for the case of methanol conversion from a single molecule $\left(\Delta F^{\ddagger}=142 \pm 3\right.$ $\mathrm{kJ} / \mathrm{mol}$ ) with that for the higher methanol loading of five methanol molecules per single active site unit cell $\left(\Delta F^{\ddagger}=149\right.$ \pm 2 ), no significant influence on methylation barrier is observed. Also, there is no significant difference between $\Delta F$ and $\Delta F^{\ddagger}$ because methanol remains protonated in the presence of other methanol molecules, as discussed in the previous section. For three methanol molecules per unit cell, we see a decrease in $\Delta F$ with increasing acid site density. The highest methylation barrier, encountered in the three methanol molecules absorbed in a single acid site zeolite unit cell, could be due to the methanol cluster being positioned further from the active site. Based on the MD simulation results in Figure 5, we find that the center of the methanol cluster is 4.48 $\AA$ from the active site, which is the farthest out of all other studied cases. This observation may also explain the difference in the methoxylation barrier when having a second acid site, where, from the MD geometric analysis, we show that the methanol cluster is closer $(3.06 \AA)$ to the active site. The acid proton of the second acid site (T8) has a repelling effect toward the positively charged methanol cluster, causing the methanol cluster to be closer to the opposite active site (T12), as illustrated in Figure 7A. Thus, including additional methanol molecules results in another preorganization of the methanol clusters closer to the active acid site, yielding lower barriers.

Returning to systems with five methanol molecules, we find that the barrier observed in our simulations drops significantly with the increase in reactant loading, from $169 \pm 5$, when having three methanol molecules, as described in the previous case, to $142 \pm 2 \mathrm{~kJ} / \mathrm{mol}$. The influence of the methanol loading on the methylation barrier could be due to the confinement effects determined by the additional methanol molecules in the zeolite pore that would influence the polarity of the electronic density around the reactant and keep the methanol molecule closer to the active site. We also note that, for $\mathrm{Si} / \mathrm{Al}$ ratios of 95, comparison to previous work implies that a reduction in $\Delta F$ occurs with elevated temperature $(139 \pm 2 \mathrm{~kJ} / \mathrm{mol}$ at 623 $\mathrm{K}) .{ }^{21}$ In the latter case, the high temperatures are thought to have a destabilizing effect, probably due to the higher entropy penalty for methanol cluster formation, which is also observed in the simulations conducted at $670 \mathrm{~K}$ in Section 3.1.1. The higher temperatures would facilitate a smooth breaking and rearrangement of the hydrogen bonds within the methanol cluster or on the active site; ${ }^{21}$ the same behavior is unlikely at low temperatures as the methanol cluster is very stable, and hence our results are slightly higher in free energy.

Further analysis of the five methanol methylation cases shows that the presence of the second acid site would greatly lower the methylation barrier. Initially, in the NPT equilibration of the MD simulations, three methanol molecules coordinated with the T12 acid site and two on the other T8 site, in the vicinity of the second deprotonated active site. As the MTD simulation proceeds, the trimer of methanol molecules forms a linear chain across the zeolite ring, thereby interacting with both T12 and T8 sites simultaneously (Figure 7B). The formation of this structure could lead to a concerted polarization effect along the $\mathrm{O}-\mathrm{H}$ bonds of the methanol trimer, which contributes to the abstraction of electron density from the $\mathrm{H}-\mathrm{O}-\mathrm{H}^{+}$group and, in turn, lengthening of the $\mathrm{C}-$ $\mathrm{O}$ bond (Figure $7 \mathrm{~B})$, leading to a lower activation barrier (112 $\pm 2 \mathrm{~kJ} / \mathrm{mol}$ ) than calculated previously for less acidic zeolites. $^{21}$ Experimental studies find that methylation occurs faster at higher temperatures; ${ }^{16}$ our simulations with one acid site per unit cell support this observation, as the activation barrier at $300 \mathrm{~K}\left(\Delta F^{\neq}=149 \pm 2 \mathrm{~kJ} / \mathrm{mol}\right)$ is significantly higher 
Scheme 2. Proposed Methylation and DME Formation Reaction Paths at Low Temperatures and High Pressure in a "Paired" Active Site Environment

\begin{tabular}{|c|}
\hline $\begin{array}{l}\text { A) Homo and hetero-association: } \\
2 \mathrm{CH}_{3} \mathrm{OH} \leftrightarrow \mathrm{CH}_{3} \mathrm{OH}_{2}^{+}+\mathrm{CH}_{3} \mathrm{O}^{-} \\
2 \mathrm{CH}_{3} \mathrm{OH}+\mathrm{ZeOH} \leftrightarrow 2 \mathrm{CH}_{3} \mathrm{OH} \cdots \mathrm{H}^{+} \cdots \mathrm{ZeO}^{-}\end{array}$ \\
\hline $\begin{array}{l}\text { B) Methylation path: } \\
\mathrm{CH}_{3} \mathrm{OH}_{2}^{+}+\mathrm{CH}_{3} \mathrm{O}^{-}+\mathrm{ZeOH} \leftrightarrow \mathrm{CH}_{3} \mathrm{OH}_{2}^{+}+\mathrm{CH}_{3} \mathrm{O}^{-} \cdots \mathrm{H}^{+} \cdots \mathrm{ZeO}^{-} \\
\mathrm{ZeO}^{-}+\mathrm{CH}_{3} \mathrm{OH}_{2}^{+}+\mathrm{CH}_{3} \mathrm{O}^{-} \cdots \mathrm{H}^{+} \cdots \mathrm{ZeO}^{-} \leftrightarrow \mathrm{ZeOCH}_{3}+\mathrm{H}_{2} \mathrm{O}+\mathrm{CH}_{3} \mathrm{O}^{-} \cdots \mathrm{H}^{+} \cdots \mathrm{ZeO}^{-}\end{array}$ \\
\hline $\begin{array}{l}\text { C) Direct DME formation path: } \\
\mathrm{ZeOH}+\mathrm{CH}_{3} \mathrm{OH}_{2}^{+}+\mathrm{CH}_{3} \mathrm{O}^{-} \cdots \mathrm{H}^{+} \cdots \mathrm{ZeO}^{-} \leftrightarrow \mathrm{ZeOH}+\mathrm{CH}_{3} \mathrm{OCH}_{3}+\mathrm{H}_{2} \mathrm{O}+\mathrm{ZeOH}\end{array}$ \\
\hline
\end{tabular}

than the barrier at $623 \mathrm{~K}\left(\Delta F^{\ddagger}=139 \pm 2 \mathrm{~kJ} / \mathrm{mol}\right)$, obtained in a previous work. ${ }^{21}$ Furthermore, it should also be noted that the change in temperature will also influence the reaction rate constants according to the Eyring equation.

At low temperatures, the dominant methanol conversion pathway is reported to be a direct formation of $\mathrm{DME},{ }^{68}$ rather than framework methylation, which is active at high temperatures; however, experimental reports suggest that surface methoxy groups are formed initially when synthesizing a zeolite with "paired" acid sites. ${ }^{41}$ Methanol also homoassociates at high concentrations, ${ }^{69}$ which increases the acidity of the environment (Scheme 2A), and may facilitate room temperature methylation that only occurs at high methanol loading. The large methanol clusters, present at lower temperatures, would not only stabilize the charge distribution corresponding to homoassociation (Scheme 2B) but also facilitate the existence of basic Lewis sites, which would aid the methyl transfer in the "paired" active site environment. However, at low loadings, the methyl transfer is more likely to occur on an additional methanol molecule because of a more favorable molecular orientation (Scheme 2C). We will analyze these concepts further in a future study.

In our analysis of the assisted methanol conversion into a methylated zeolite framework, we find that the backward reaction (from product to reactant) becomes increasingly favorable as additional methanol molecules are included in the simulation (Table S9, Section S7, Supporting Information). The kinetic rates calculated with the free-energy barrier are many orders of magnitude higher for the backward reaction, implying that this would be a significant limitation for the stability of the methoxide group. The ease of the backward conversion, from a water molecule (product state) into methanol, with increasing quantities of methanol is promoted by the methanol molecules (cluster) polarizing the water molecule when close to the methyl fragment (similar to the lower barrier for framework deprotonation); the same effect is not observed in the single methanol methylation because no polarization can occur. Previous studies also highlighted the key role of protonated water cluster alcohol dehydration catalysis. Specifically, the hydronium clusters would associate through hydrogen bonds with cyclohexanol and, coupled with the confinement effects determined by the zeolite pores, were shown to increase the activation entropy and reaction rate. ${ }^{70}$

\section{SUMMARY AND CONCLUSIONS}

Using $a b$ initio $\mathrm{MD}$ simulations, the dynamic behavior of methanol has been studied in the zeolite H-ZSM-5 in order to elucidate the initial stages of the MTH process at room temperature and investigate the influence of higher methanol loading and higher acid site density. We have investigated the interaction of methanol with different Brønsted acid sites in detail to understand the role of methanol loading and local zeolite environment on framework methylation. Our simulations suggest that the methanol molecules form clusters around the active site, which then facilitate acid site deprotonation. The subsequent charged methanol clusters stabilize around the active site at a distance that is dependent on the number of methanol molecules in the cluster. Inclusion of a second acid site in close proximity affects the stability of the methanol cluster and favors the energy barrier for subsequent methylation of the framework. Interestingly, the combined effect of higher methanol molecules and higher acid site density may create favorable preorganization patterns for methylation pathways.

To understand further the reaction pathway for framework methylation, enhanced sampling MD simulations were performed. For low methanol loadings, the reaction barriers are consistent with varying acid site density; however, at higher acid site density, the energy barriers are significantly altered by concerted interactions between acid sites that can lower reaction barriers. Confinement effects and additional methanol molecules play some role in stabilizing the methanol clusters and aiding the methylation process, though not as extensively as experimentally observed, which hints at a different type of active site (such as an extra-framework aluminum, framework defects) or a higher acid density being involved in the methylation process, which in turn will require further investigations through a broader analysis of other T-sites. To analyze quantitatively the polarization effect of the second acid site on the methanol conversion, future studies will involve the determination of individual atomic charges for methanol conversion reactions in the presence of secondary active sites with varying acid strengths.

\section{ASSOCIATED CONTENT}

\section{Supporting Information}

The Supporting Information is available free of charge at https://pubs.acs.org/doi/10.1021/acscatal.0c01454.

Data used in the determination of the unit cell parameters for NVT MD simulations; analysis of methanol loading per pore volume; geometric analysis of MD simulations; MTD cell parameters and analysis of methodology; quantum mechanics/molecular mechanics 
geometry optimization of single methanol adsorption; and kinetic and free-energy analysis (PDF)

\section{AUTHOR INFORMATION}

\section{Corresponding Authors}

Pieter Cnudde - Center for Molecular Modeling, Ghent University, Ghent 9000, Belgium; 다이이.org/0000-00026735-0078; Email: pieter.cnudde@ugent.be

Veronique Van Speybroeck - Center for Molecular Modeling, Ghent University, Ghent 9000, Belgium; 이이.org/00000003-2206-178X; Email: veronique.vanspeybroeck@ ugent.be

Andrew J. Logsdail - Cardiff Catalysis Institute, School of Chemistry, Cardiff University, Cardiff CF10 3AT, U.K.; (1) orcid.org/0000-0002-2277-415X; Email: LogsdailA@ cardiff.ac.uk

\section{Authors}

Stefan A. F. Nastase - Cardiff Catalysis Institute, School of Chemistry, Cardiff University, Cardiff CF10 3AT, U.K.

Louis Vanduyfhuys - Center for Molecular Modeling, Ghent University, Ghent 9000, Belgium

Kristof De Wispelaere - Center for Molecular Modeling, Ghent University, Ghent 9000, Belgium; 다이이.org/0000-00031147-7050

C. Richard A. Catlow - Cardiff Catalysis Institute, School of Chemistry, Cardiff University, Cardiff CF10 3AT, U.K.; Department of Chemistry, University College London, London WC1E 6BT, U.K.; UK Catalysis Hub, Research Complex at Harwell, Science and Technology Facilities Council, Rutherford Appleton Laboratory, Oxford OX11 OFA, U.K.

Complete contact information is available at:

https://pubs.acs.org/10.1021/acscatal.0c01454

\section{Notes}

The authors declare no competing financial interest.

The raw data from which results were derived is available to access at DOI: 10.17035/d.2020.0111777454.

\section{ACKNOWLEDGMENTS}

We are grateful to the School of Chemistry, Cardiff University, for financial support through the International Collaboration Seedcorn Fund. The simulations in this research were undertaken using the supercomputing facilities at the Cardiff University operated by Advanced Research Computing at Cardiff (ARCCA) on behalf of the Cardiff Supercomputing Facility and the HPC Wales and Supercomputing Wales (SCW) projects. We acknowledge the support of the latter, which is part-funded by the European Regional Development Fund (ERDF) via the Welsh Government. We also acknowledge access to The UK ARCHER High Performance Computing facility through our membership of the UK's HPC Materials Chemistry Consortium (MCC), which is funded by EPSRC grant (EP/L000202). V.V.S., P.C., K.D.W., and L.V. acknowledge the Research Foundation-Flanders (FWO), the Research Board of Ghent University (BOF), and funding from the European Union's Horizon 2020 research and innovation program (consolidator ERC Grant Agreement no. 647755-DYNPOR (2015-2020)). The computational resources and services used were partially provided by the Ghent University (Stevin Supercomputer Infrastructure) and the VSC (Flemish Supercomputer Center), funded by the Research Foundation-Flanders (FWO).

\section{REFERENCES}

(1) Chang, C.; Silvestri, A. J. The Conversion of Methanol and Other O-Compounds to Hydrocarbons over Zeolite Catalysts. J. Catal. 1977, 47, 249-259.

(2) Guisnet, M.; Gilson, J.-P. Zeolites for Cleaner Technologies; Imperial College Press: London, 2002; p 391.

(3) Tian, P.; Wei, Y.; Ye, M.; Liu, Z. Methanol to Olefins (MTO): From Fundamentals to Commercialization. ACS Catal. 2015, 5, $1922-1938$

(4) Sudarsanam, P.; Peeters, E.; Makshina, E. V.; Parvulescu, V. I.; Sels, B. F. Advances in Porous and Nanoscale Catalysts for Viable Biomass Conversion. Chem. Soc. Rev. 2019, 48, 2366-2421.

(5) Bjørgen, M.; Olsbye, U.; Petersen, D.; Kolboe, S. The Methanolto-Hydrocarbons Reaction: Insight into the Reaction Mechanism from [12C]Benzene and [13C]Methanol Coreactions over Zeolite $\mathrm{H}$ Beta. J. Catal. 2004, 221, 1-10.

(6) Yarulina, I.; Chowdhury, A. D.; Meirer, F.; Weckhuysen, B. M.; Gascon, J. Recent Trends and Fundamental Insights in the Methanolto-Hydrocarbons Process. Nat. Catal. 2018, 1, 398-411.

(7) Hemelsoet, K.; Van der Mynsbrugge, J.; De Wispelaere, K.; Waroquier, M.; Van Speybroeck, V. Unraveling the Reaction Mechanisms Governing Methanol-to-Olefins Catalysis by Theory and Experiment. ChemPhysChem 2013, 14, 1526-1545.

(8) Olsbye, U.; Svelle, S.; Bjørgen, M.; Beato, P.; Janssens, T. V. W.; Joensen, F.; Bordiga, S.; Lillerud, K. P. Conversion of Methanol to Hydrocarbons: How Zeolite Cavity and Pore Size Controls Product Selectivity. Angew. Chem., Int. Ed. 2012, 51, 5810-5831.

(9) Haw, J. F.; Marcus, D. M. Well-Defined (Supra)Molecular Structures in Zeolite Methanol-to-Olefin Catalysis. Top. Catal. 2005, $34,41-48$.

(10) Wang, J.; Wei, Y.; Li, J.; Xu, S.; Zhang, W.; He, Y.; Chen, J.; Zhang, M.; Zheng, A.; Deng, F.; Guo, X.; Liu, Z. Direct Observation of Methylcyclopentenyl Cations (MCP+) and Olefin Generation in Methanol Conversion over TON Zeolite. Catal. Sci. Technol. 2016, 6, 89-97.

(11) Haw, J. F.; Nicholas, J. B.; Song, W.; Deng, F.; Wang, Z.; Xu, T.; Heneghan, C. S. Roles for Cyclopentenyl Cations in the Synthesis of Hydrocarbons from Methanol on Zeolite Catalyst HZSM-5. J. Am. Chem. Soc. 2000, 122, 4763-4775.

(12) Kiricsi, I.; Förster, H.; Tasi, G.; Nagy, J. B. Generation, Characterization, and Transformations of Unsaturated Carbenium Ions in Zeolites. Chem. Rev. 1999, 99, 2085-2114.

(13) Stöcker, M. Methanol-to-Hydrocarbons: Catalytic Materials and Their Behaviour. Microporous Mesoporous Mater. 1999, 29, 3-48.

(14) Lesthaeghe, D.; Van Speybroeck, V.; Marin, G. B.; Waroquier, M. The Rise and Fall of Direct Mechanisms in Methanol-to-Olefin Catalysis: An Overview of Theoretical Contributions. Ind. Eng. Chem. Res. 2007, 46, 8832-8838.

(15) Martínez-Espín, J. S.; De Wispelaere, K.; Janssens, T. V. W.; Svelle, S.; Lillerud, K. P.; Beato, P.; Van Speybroeck, V.; Olsbye, U. Hydrogen Transfer versus Methylation: On the Genesis of Aromatics Formation in the Methanol-To-Hydrocarbons Reaction over H-ZSM5. ACS Catal. 2017, 7, 5773-5780.

(16) Wang, W.; Buchholz, A.; Seiler, M.; Hunger, M. Evidence for an Initiation of the Methanol-to-Olefin Process by Reactive Surface Methoxy Groups on Acidic Zeolite Catalysts. J. Am. Chem. Soc. 2003, $125,15260-15267$.

(17) Wang, W.; Seiler, M.; Hunger, M. Role of Surface Methoxy Species in the Conversion of Methanol to Dimethyl Ether on Acidic Zeolites Investigated by in Situ Stopped-Flow MAS NMR Spectroscopy. J. Phys. Chem. B 2001, 105, 12553-12558.

(18) Müller, S.; Liu, Y.; Vishnuvarthan, M.; Sun, X.; Van Veen, A. C.; Haller, G. L.; Sanchez-Sanchez, M.; Lercher, J. A. Coke Formation and Deactivation Pathways on H-ZSM-5 in the Conversion of Methanol to Olefins. J. Catal. 2015, 325, 48-59. 
(19) Schmidt, F.; Hoffmann, C.; Giordanino, F.; Bordiga, S.; Simon, P.; Carrillo-Cabrera, W.; Kaskel, S. Coke Location in Microporous and Hierarchical ZSM-5 and the Impact on the MTH Reaction. J. Catal. 2013, 307, 238-245.

(20) Svelle, S.; Visur, M.; Olsbye, U.; Saepurahman; Bjørgen, M. Mechanistic Aspects of the Zeolite Catalyzed Methylation of Alkenes and Aromatics with Methanol: A Review. Top. Catal. 2011, 54, 897.

(21) Van der Mynsbrugge, J.; Moors, S. L. C.; De Wispelaere, K.; Van Speybroeck, V. Insight into the Formation and Reactivity of Framework-Bound Methoxide Species in h-Zsm-5 from Static and Dynamic Molecular Simulations. Chem CatChem 2014, 6, 1906-1918.

(22) De Wispelaere, K.; Martínez-Espín, J. S.; Hoffmann, M. J.; Svelle, S.; Olsbye, U.; Bligaard, T. Understanding Zeolite-Catalyzed Benzene Methylation Reactions by Methanol and Dimethyl Ether at Operating Conditions from First Principle Microkinetic Modeling and Experiments. Catal. Today 2018, 312, 35-43.

(23) Jones, A. J.; Iglesia, E. Kinetic, Spectroscopic, and Theoretical Assessment of Associative and Dissociative Methanol Dehydration Routes in Zeolites. Angew. Chem., Int. Ed. 2014, 53, 12177-12181.

(24) Maihom, T.; Boekfa, B.; Sirijaraensre, J.; Nanok, T.; Probst, M.; Limtrakul, J. Reaction Mechanisms of the Methylation of Ethene with Methanol and Dimethyl Ether over H-ZSM-5: An ONIOM Study. J. Phys. Chem. C 2009, 113, 6654-6662.

(25) Forester, T. R.; Wong, S.-T.; Howe, R. F. In Situ Fourier Transform i.r. Observation of Methylating Species in ZSM-5. J. Chem. Soc., Chem. Commun. 1986, 0, 1611-1613.

(26) Forester, T. R.; Howe, R. F. In Situ FTIR Studies of Methanol and Dimethyl Ether in ZSM-5. J. Am. Chem. Soc. 1987, 109, 50765082.

(27) Cheung, P.; Bhan, A.; Sunley, G.; Law, D.; Iglesia, E. Site Requirements and Elementary Steps in Dimethyl Ether Carbonylation Catalyzed by Acidic Zeolites. J. Catal. 2007, 245, 110-123.

(28) Ivanova, I. I.; Corma, A. Surface Species Formed and Their Reactivity during the Alkylation of Toluene by Methanol and Dimethyl Ether on Zeolites As Determined byin Situ13C MAS NMR. J. Phys. Chem. B 1997, 101, 547-551.

(29) Salvador, P.; Kladnig, W. Surface Reactivity of Zeolites Type HY and Na-Y with Methanol. J. Chem. Soc., Faraday Trans. 1 1977, 73, $1153-1168$.

(30) Matam, S. K.; Howe, R. F.; Thetford, A.; Catlow, C. R. A. Room Temperature Methoxylation in Zeolite H-ZSM-5: An Operando DRIFTS/Mass Spectrometric Study. Chem. Commun. 2018, 54, 12875-12878.

(31) O’Malley, A. J.; Parker, S. F.; Chutia, A.; Farrow, M. R.; Silverwood, I. P.; García-Sakai, V.; Catlow, C. R. A. Room Temperature Methoxylation in Zeolites: Insight into a Key Step of the Methanol-to-Hydrocarbons Process. Chem. Commun. 2016, 52, 2897-2900.

(32) Matam, S. K.; Nastase, S. A. F.; Logsdail, A. J.; Catlow, C. R. A. Methanol Loading Dependent Methoxylation in Zeolite H-ZSM-5. Chem. Sci. 2020, 11, 6805-6814.

(33) Govind, N.; Andzelm, J.; Reindel, K.; Fitzgerald, G. ZeoliteCatalyzed Hydrocarbon Formation from Methanol: Density Functional Simulations. Int. J. Mol. Sci. 2002, 3, 423-434.

(34) Blaszkowski, S. R.; van Santen, R. A. Density Functional Theory Calculations of the Activation of Methanol by a Broensted Zeolitic Proton. J. Phys. Chem. 1995, 99, 11728-11738.

(35) Kim, C. W.; Heo, N. H.; Seff, K. Framework Sites Preferred by Aluminum in Zeolite ZSM-5. Structure of a Fully Dehydrated, Fully Cs+-Exchanged ZSM-5 Crystal (MFI, Si/Al = 24). J. Phys. Chem. C 2011, 115, 24823-24838.

(36) Moors, S. L. C.; De Wispelaere, K.; Van Der Mynsbrugge, J.; Waroquier, M.; Van Speybroeck, V. Molecular Dynamics Kinetic Study on the Zeolite-Catalyzed Benzene Methylation in ZSM-5. ACS Catal. 2013, 3, 2556-2567.

(37) Rey, J.; Raybaud, P.; Chizallet, C.; Bučko, T. Competition of Secondary versus Tertiary Carbenium Routes for the Type B Isomerization of Alkenes over Acid Zeolites Quantified by Ab Initio Molecular Dynamics Simulations. ACS Catal. 2019, 9, 9813-9828.
(38) Knott, B. C.; Nimlos, C. T.; Robichaud, D. J.; Nimlos, M. R.; Kim, S.; Gounder, R. Consideration of the Aluminum Distribution in Zeolites in Theoretical and Experimental Catalysis Research. ACS Catal. 2018, 8, 770-784.

(39) Loewenstein, W. The Distribution of Aluminum in the Tetrahedra of Silicates and Aluminates. Am. Mineral. 1954, 39, $92-$ 96.

(40) Dempsey, E.; Kuehl, G. H.; Olson, D. H. Variation of the Lattice Parameter with Aluminum Content in Synthetic Sodium Faujasites. Evidence for Ordering of the Framework Ions. J. Phys. Chem. 1969, 73, 387-390.

(41) Di Iorio, J. R.; Nimlos, C. T.; Gounder, R. Introducing Catalytic Diversity into Single-Site Chabazite Zeolites of Fixed Composition via Synthetic Control of Active Site Proximity. ACS Catal. 2017, 7, 6663-6674.

(42) Vanduyfhuys, L.; Ghysels, A.; Rogge, S. M. J.; Demuynck, R.; Van Speybroeck, V. Semi-Analytical Mean-Field Model for Predicting Breathing in Metal-Organic Frameworks. Mol. Simul. 2015, 41, 1311-1328.

(43) Bailleul, S.; Yarulina, I.; Hoffman, A. E. J.; Dokania, A.; AbouHamad, E.; Chowdhury, A. D.; Pieters, G.; Hajek, J.; De Wispelaere, K.; Waroquier, M.; Gascon, J.; Van Speybroeck, V. A Supramolecular View on the Cooperative Role of Brønsted and Lewis Acid Sites in Zeolites for Methanol Conversion. J. Am. Chem. Soc. 2019, 141, 14823-14842.

(44) VandeVondele, J.; Krack, M.; Mohamed, F.; Parrinello, M.; Chassaing, T.; Hutter, J. Quickstep: Fast and Accurate Density Functional Calculations Using a Mixed Gaussian and Plane Waves Approach. Comput. Phys. Commun. 2005, 167, 103-128.

(45) Yang, K.; Zheng, J.; Zhao, Y.; Truhlar, D. G. Tests of the RPBE, RevPBE, $\tau$-HCTHhyb, $\omega$ b97X-D, and MOHLYP Density Functional Approximations and 29 Others against Representative Databases for Diverse Bond Energies and Barrier Heights in Catalysis. J. Chem. Phys. 2010, 132, 164117

(46) Grimme, S.; Antony, J.; Ehrlich, S.; Krieg, H. A Consistent and Accurate Ab Initio Parametrization of Density Functional Dispersion Correction (DFT-D) for the 94 Elements H-Pu. J. Chem. Phys. 2010, 132,154104

(47) Lippert, G.; Hutter, J.; Parrinello, M. The Gaussian and Augmented-Plane-Wave Density Functional Method for Ab Initio Molecular Dynamics Simulations. Theor. Chem. Acc. 1999, 103, 124140 .

(48) Goedecker, S.; Teter, M.; Hutter, J. Separable Dual-Space Gaussian Pseudopotentials. Phys. Rev. B: Condens. Matter Mater. Phys. 1996, 54, 1703-1710.

(49) Nosé, S. A Unified Formulation of the Constant Temperature Molecular Dynamics Methods. J. Chem. Phys. 1984, 81, 511-519.

(50) Hoover, W. G. Canonical Dynamics: Equilibrium Phase-Space Distributions. Phys. Rev. A: At., Mol., Opt. Phys. 1985, 31, 1695-1697.

(51) Martyna, G. J.; Tobias, D. J.; Klein, M. L. Constant Pressure Molecular Dynamics Algorithms. J. Chem. Phys. 1994, 101, 41774189.

(52) Nastase, S. A. F.; O’Malley, A. J.; Catlow, C. R. A.; Logsdail, A. J. Computational QM/MM Investigation of the Adsorption of MTH Active Species in H-Y and H-ZSM-5. Phys. Chem. Chem. Phys. 2019, 21, 2639-2650.

(53) Wu, X.; Chen, Y.; Yamaguchi, T. Hydrogen Bonding in Methanol Studied by Infrared Spectroscopy. J. Mol. Spectrosc. 2007, 246, 187-191.

(54) Bussi, G.; Laio, A.; Parrinello, M. Equilibrium Free Energies from Nonequilibrium Metadynamics. Phys. Rev. Lett. 2006, 96, 090601.

(55) Laio, A.; Parrinello, M. Escaping Free-Energy Minima. Proc. Natl. Acad. Sci. U.S.A. 2002, 99, 12562-12566.

(56) Laio, A.; Gervasio, F. L. Metadynamics: A Method to Simulate Rare Events and Reconstruct the Free Energy in Biophysics, Chemistry and Material Science. Rep. Prog. Phys. 2008, 71, 126601.

(57) Bučko, T.; Chibani, S.; Paul, J.-F.; Cantrel, L.; Badawi, M. Dissociative Iodomethane Adsorption on Ag-MOR and the 
Formation of AgI Clusters: An Ab Initio Molecular Dynamics Study. Phys. Chem. Chem. Phys. 2017, 19, 27530-27543.

(58) Bailleul, S.; Rogge, S. M. J.; Vanduyfhuys, L.; Van Speybroeck, $\mathrm{V}$. Insight into the Role of Water on the Methylation of Hexamethylbenzene in H-SAPO-34 from First Principle Molecular Dynamics Simulations. Chem CatChem 2019, 11, 3993-4010.

(59) Omojola, T.; Cherkasov, N.; McNab, A. I.; Lukyanov, D. B.; Anderson, J. A.; Rebrov, E. V.; van Veen, A. C. Mechanistic Insights into the Desorption of Methanol and Dimethyl Ether Over ZSM-5 Catalysts. Catal. Lett. 2018, 148, 474-488.

(60) Lee, C.-C.; Gorte, R. J.; Farneth, W. E. Calorimetric Study of Alcohol and Nitrile Adsorption Complexes in H-ZSM-5. J. Phys. Chem. B 1997, 101, 3811-3817.

(61) Stoyanov, E. S.; Stoyanova, I. V.; Reed, C. A. IR Spectroscopic Properties of $\mathrm{H}(\mathrm{MeOH}) \mathrm{N}+$ Clusters in the Liquid Phase: Evidence for a Proton Wire. Chem.-Eur. J. 2008, 14, 3596-3604.

(62) Zecchina, A.; Bordiga, S.; Spoto, G.; Scarano, D.; Spanò, G.; Geobaldo, F. IR spectroscopy of neutral and ionic hydrogen-bonded complexes formed upon interaction of $\mathrm{CH} 3 \mathrm{OH}, \mathrm{C} 2 \mathrm{H} 5 \mathrm{OH}$, (CH3)2O, (C2H5)2O and C4H8O with H-Y, H-ZSM-5 and Hmordenite: comparison with analogous adducts formed on the $\mathrm{H}$ Nafion superacidic membrane. J. Chem. Soc., Faraday Trans. 1996, 92, $4863-4875$.

(63) Anderson, M. W.; Klinowski, J.; Barrie, P. J. Proton magicangle-spinning NMR studies of the adsorption of alcohols on molecular sieve catalysts. J. Phys. Chem. 1991, 95, 235-239.

(64) Koller, H.; Engelhardt, G.; van Santen, R. A. The Dynamics of Hydrogen Bonds and Proton Transfer in Zeolites - Joint Vistas from Solid-State NMR and Quantum Chemistry. Top. Catal. 1999, 9, 163180.

(65) Plant, D. F.; Maurin, G.; Bell, R. G. Diffusion of Methanol in Zeolite NaY: A Molecular Dynamics Study. J. Phys. Chem. B 2007, 111, 2836-2844.

(66) Fifen, J. J.; Nsangou, M.; Dhaouadi, Z.; Motapon, O.; Jaidane, N.-E. Solvation Energies of the Proton in Methanol. J. Chem. Theory Comput. 2013, 9, 1173-1181.

(67) O’Malley, A. J.; Logsdail, A. J.; Sokol, A. A.; Catlow, C. R. A. Modelling Metal Centres, Acid Sites and Reaction Mechanisms in Microporous Catalysts. Faraday Discuss. 2016, 188, 235-255.

(68) Ortega, C.; Rezaei, M.; Hessel, V.; Kolb, G. Methanol to Dimethyl Ether Conversion over a ZSM-5 Catalyst: Intrinsic Kinetic Study on an External Recycle Reactor. Chem. Eng. J. 2018, 347, 741753.

(69) Monakhova, Y. B.; Mushtakova, S. P. Methanol and Acetonitrile Associates in Aqueous and Chloroform Solutions According to $1 \mathrm{H}$ NMR Spectroscopic Data. Russ. J. Phys. Chem. A 2014, 88, 798-802.

(70) Liu, Y.; Vjunov, A.; Shi, H.; Eckstein, S.; Camaioni, D. M.; Mei, D.; Baráth, E.; Lercher, J. A. Enhancing the Catalytic Activity of Hydronium Ions through Constrained Environments. Nat. Commun. 2017, 8, 14113. 